$\xi=-1$

\title{
An Optimal Path Identification in the Intermodal Freight Transportation Network
}

\author{
Adel Gohari ${ }^{1 *}$, Abdul Nasir Bin Matori ${ }^{2}$, Khamaruzaman Wan Yusof $^{3}$, Iraj Toloue ${ }^{4}$, Khin Cho Myint ${ }^{5}$ \\ 1,2,3,4,5 Department of Civil and Environmental Engineering, Univeristi Teknologi PETRONAS, Malaysia \\ *Corresponding author:adel.gohari@gmail.com
}

\begin{abstract}
Intermodal transportation is a research topic of great interest at present. This paper presents a route choice analysis on an intermodal freight transportation network. The aim of this study was to determine the optimum route and mode of transportation based on least distance and least time criteria for the movement of containers from origin to the destination. Geographic Information System (GIS) was adopted to build the hypothetical freight transportation network and MATLAB software was used to model the travel distance and travel time. The results showed that the model can be used effectively to identify the shortest path and modes of transportation according to objective functions.
\end{abstract}

Keywords: Intermodal transportation; Freight; Optimum route; route choice; Mode choice.

\section{Introduction}

Transportation sector is one of the major components of globalization and plays very significant role in daily activities and economy of each society. In particular, freight transportation is one of today's most important economic activities, not only as measured by its share of nation's Gross National Product (GNP), but also by the increasing influence that transportation and distribution of goods have on the performance of many economic sectors. The demand of freight transportation is derived from all the activities needed to move goods from origins to the destinations, including trade, logistics and transportation [1]. The demand for freight transportation has increased in response to population growth and expansion in economic activities. Movement of goods needs infrastructure such as roads and railways, and vehicles like trucks, trains, ships and aircrafts. Quality, type, size and capacity of infrastructures and vehicles can directly impact on freight transportation.

Freight transportation includes multimodal and intermodal transportation systems. Multimodal transportation is defined as the movement of commodities by using at least two different modes of transportation sequentially [2] and its transportation unit can be in a box, container, transported via road, rail vehicles or vessels. Intermodal freight transportation is a particular type of multimodal transportation where loads are transported from an origin to a destination in one and the same intermodal transportation unit (e.g. a Twenty-foot Equivalent Unit (TEU1) container) without handling of the goods themselves when changing modes [3]. Intermodality addresses the movement of goods by using different transportation modes and it can be an ideal tool for shippers as providing them with better routing choices based on their requirements. According to Muller[4], the concept of logistically linking a freight movement with two or more transport modes is centuries old. However, recent focus on this particular type of transportation is due to radical developments in the technology of freight transportation brought by containerization.

Route choice analysis throughout the transport network is to find the suitable route between two designated points as origin and destination based on different objective functions such as travel distance, travel time, travel cost, emission, etc. This study focuses on finding an optimal route in terms of travel distance and travel time criteria throughout a hypothetical intermodal freight transport network. The research objective was achieved by applying Dijkstra's algorithm in MATLAB environment to solve the shortest path problem in intermodal freight transport networks.

\section{Literature Review}

Intermodal transportation includes both national and international levels. Waterway and airway are the main modes of transport in international intermodal transportation; whereas road and railroad or their combination play significant roles in national intermodal transportation. There are several research papers on intermodal routing methods. Barnhart and Ratliff [5] discussed different methods for determining the minimum cost intermodal routings. Boardman et al. [6] described a decision support system that implemented a robust analytical method to automate the determination of the least cost combination of transportation modes throughout a network. Bookbinder and Fox [7] obtained an optimal routings for intermodal containerized transport from Canada to Mexico. Southworth and Peterson [8] described the development and application of a single, integrated digital representation of a multimodal and transcontinental freight transportation network focused on intermodal freight routing which involve different combinations of truck, rail and water transportation. Chang [9] formulated an international intermodal routing problem as a multiobjective multimodal multi-commodity flow problem (MMMFP) with time windows and concave costs. Cho et al. [10] presented a dynamic programming algorithm to draw optimal intermodal 
freight routing and applied the algorithm to real transport paths from Busan to Rotterdam. Hu [11] modelled the system of container multimodal transportation by using integer linear programming to build the path selection for container supply chain in the context of emergency relief. Kai et al. [12] proposed an integrated model which enables selection of transport mode and optimize the transport route synthetically to fit the diversification of the transport route and transport process. Yang et al. [13] presented an intermodal network optimization model based on the principles of goal programming to examine competitiveness of different alternative routings for freight moving from China to and beyond Indian Ocean.

GIS application is a very versatile tool in many fields and more specifically in transportation and freight modeling. It is widely adopted in freight modeling due to its abilities of displaying data and handling of huge databases. Data display and manipulation can be considered as simplest usage of GIS for freight analysis. The results in GIS are in the forms of maps and usually, GIS can be interfaced with another analytical program for the purpose of map production. GIS models and intermodal network models can be integrated so that it provides a generic user friendly functional environment that enables policies evaluation to improve the cost effectiveness among competing modes. Boile [14] developed a framework to analyze and evaluate intermodal networks in a GIS environment for auto and rail commuter networks. Standifer and Walton [15] presented similar research effort but with different methodology in intermodal network creation. They modeled intermodal freight transportation in GIS environment to perform varieties of analysis through decision support system for shippers, planning agencies and researchers. Winebrake et al. [16] also presented a Geospatial Intermodal Freight Transportation (GIFT) model which was developed in GIS platform. This model was applied to identify the route from an origin to destination in an intermodal transport network for objective functions such as cost, time and emission. Comer et al. [17] used the GIFT model for the investigation of replacing marine vessels with heavy-duty trucks in the U.S. Great Lakes regions.

\section{Methodology}

An intermodal transport network can be modelled as a directed graph using two types of interconnected components, nodes and arcs [18]. Nodes represent sources, destinations and transport modal changing points (intermodal terminals), while arcs represent routes and each arc indicates one mode of transport between each pair of nodes. In this study, road, railroad and waterway were considered as three modes of freight transportation. Two types of roads were taking into account which are highway and federal road. ArcGIS was used to build the transport network. Designed transport network is as depicted in Fig. 1. It consists of point and line layers. Point layers include ports (sources), depots (destinations) and intermodal terminal points. Point number 1 and 2 were ports, point number 3 and 4 were depots and point number 5, 6 and 7 were intermodal terminal points. Line layers included roads (highway and federal roads), railroads and waterways. Each arc in the transport network was weighted with the length value based on kilometres. Moreover, MATLAB computer software was used as a platform to modelling the analysis based on Dijkstra's algorithm. The speed limit was assumed constant for each vehicle type in each segment of the network and congestion on roads was not considered.

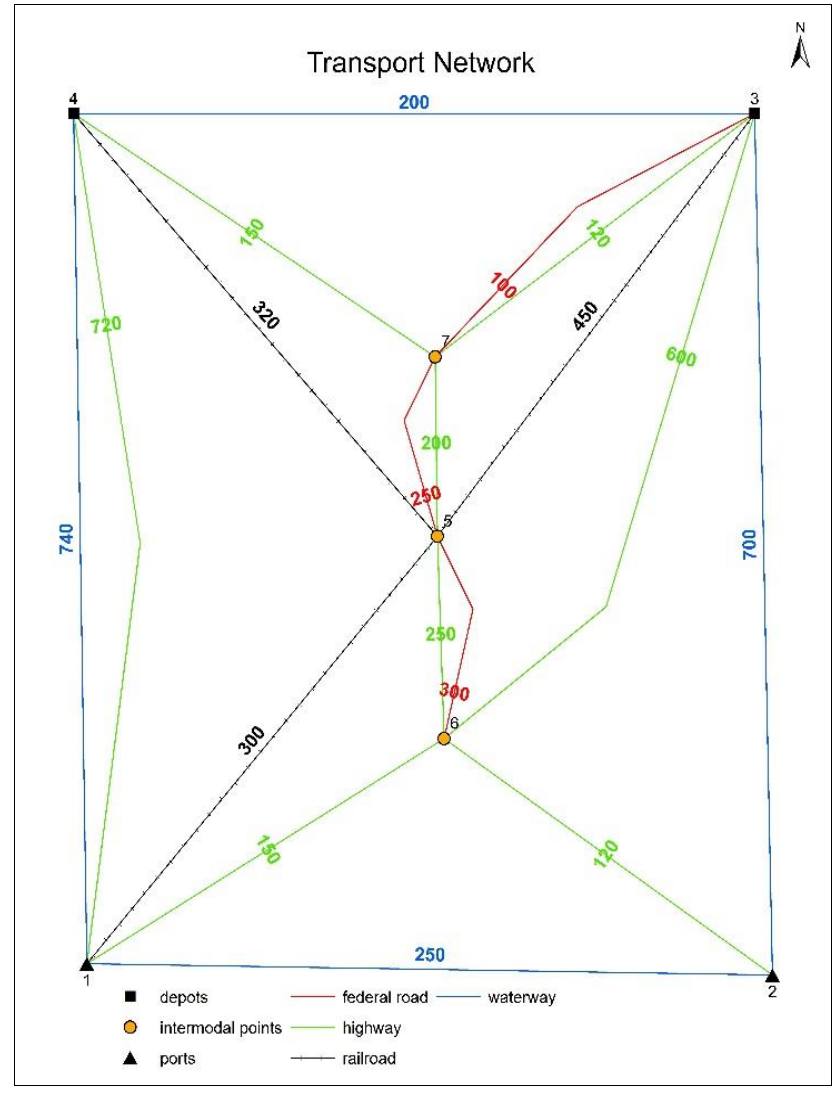

Fig. 1. Hypothetical transport network

\section{Results and Discussion}

In this study, two case studies were investigated. In case 1 , node one was the origin and node three was the destination. In case 2, node two was the origin and node four was the destination point. In order to identify the optimum route, the algorithm calculates all the possible routes from origin node to destination point and display the least-distance and least-time path as model results. The results of travel-distance based analysis is just dependent on the length of each arcs of the network, while results of travel-time based analysis is dependent on both length and speed limit of each segment of the transport network.

The results of travel distance and travel time analysis for case number one are depicted in Fig. 2 and 3 respectively. The analysis showed that there are twenty-six possible routes to move from point one to three. The result shows that the least-distance route was path 1-5-7-3 with total distance of $600 \mathrm{~km}$. This path consisted of three segments which are: from point one to five with railroad transport mode, from intermodal point five to seven with road transportation by using highway and finally from point seven to the destination point three with road transportation by using federal road. Thus, the result of travel distance analysis is using both train and truck as freight transportation modes. For the purpose of finding the short path based on travel time, it is necessary to assume speed limit for each modes of transport. The speed limit for highway, federal road, railroad and waterway were assumed to be $110 \mathrm{~km} / \mathrm{h}, 90 \mathrm{~km} / \mathrm{h}, 75 \mathrm{~km} / \mathrm{h}$ and $50 \mathrm{~km} / \mathrm{h}$ respectively. Travel time for each segment of the route was calculated according to its relationship with distance and speed limit. Results showed that the least-time shortest path was 1-6-57-3 and its total time was 6.54 hour by using truck through highway. Although the distance of railway from point 1 to 5 is 100 $\mathrm{km}$ shorter than highway route, but highway route was selected for this part of least-time route due to its higher speed. Consequently, the travel time of highway route from point 1 to 5 is 0.36 hour less than railway. Because of same reason, highway selected for travel from point 7 to 3 instead of federal road(travel time of highway is 0.02 hour less than federal road). 


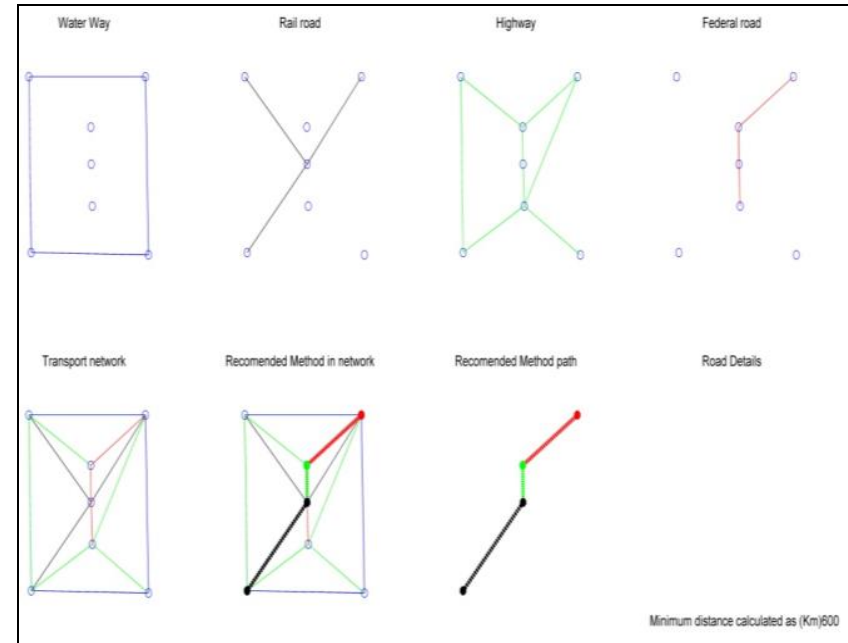

Fig. 2. Travel distance analysis from node 1 to node 3



Fig. 3. Travel time analysis from node 1 to node 3

The results of travel distance and travel time analysis for the case number two are depicted in Figs. 4 and 5 respectively. The path of 2-6-5-4 was the least-distance route with total distance $690 \mathrm{~km}$ for combination of highway and railroad as transportation mode. In terms of travel time, the route of 2-6-5-7-4 was the shortest path with total travel time of 6.54 hour by using truck and highway. According to the results, highway and truck have been chosen as least-time route and mode of transport in both cases. The main reason for this selection is the high speed advantage of highway compared to other transport modes. However, truck and highway cannot be considered as all-time feasible solution as it can cause more congestion on the roads and increase the greenhouse gas emission, especially in the case of shipment of large number of containers.

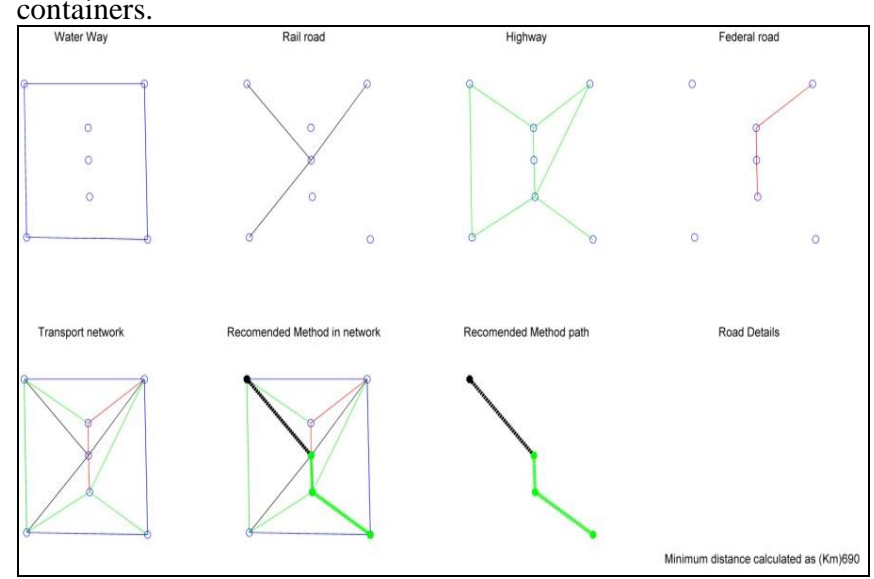

Fig. 4. Travel distance analysis from node 2 to node 4

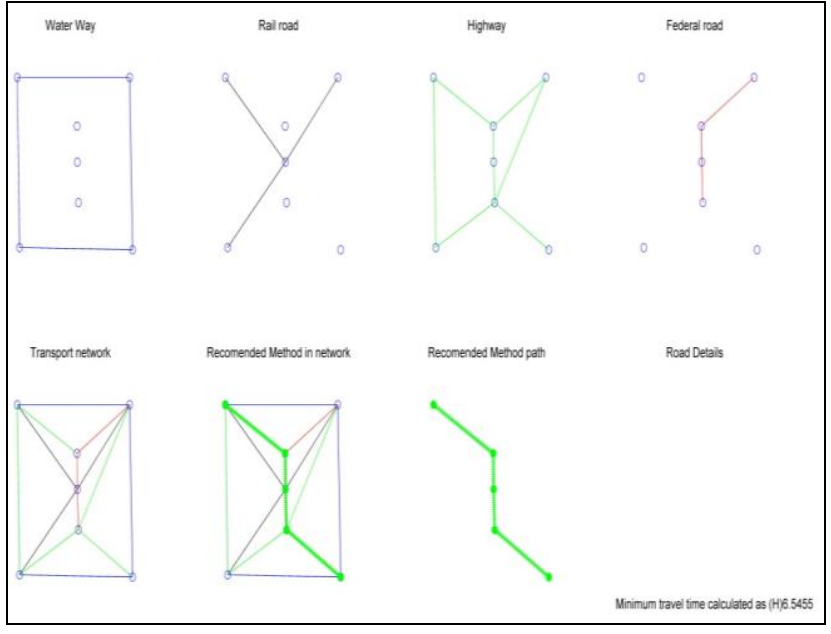

Fig. 5. Travel time analysis from node 2 to node 4

\section{Conclusion}

In this paper, the shortest path problem in an intermodal freight transport network was investigated. ArcGIS was adopted to design transport network and MATLAB was used as platform to implement Dijkstra's algorithm for the hypothetical intermodal transport network. The algorithm was applied to identify the shortest path and mode of transport based on travel distance and travel time criteria. The results showed that the model can be used effectively to identify least-distance and least-time path and modes of transportation for any origin and destination points throughout the transport network. Identification of optimum route based on time objective is beneficial for transportation of time sensitive goods. This model and approach can be developed to determine an optimum route according to some other objective functions such as travel cost and carbon dioxide emission. Transport cost is one of the most significant factors that affect mode of freight transportation and emission of carbon dioxide can negatively impact on air quality. The model also can be applied to real transport networks with consideration of network topology design for intermodal terminal points to include its transfer time, cost and emission in route calculations.

\section{References}

[1] Tavasszy, L.A., Ruijgrok, K., \&Davydenko, I. (2012), Incorporating logistics in freight transport demand models: state-of-theart and research opportunities, Transport Reviews 32, 203-219.

[2] Marczak, M., \&Hassard, J. (2010), Illustrated Glossary for Transport Statistics, ECD/Eurostat/United Nations Economic Commission, available online: http://ec.europa.eu/eurostat/documents/3859598/5911341/KSRA-10-028-EN.PDF/6ddd731e-0936-455a-be6b-eac624a83db4

[3] Crainic, T. G., \& Kim, K. H. (2007). Intermodal transportation. Handbooks in operations research and management science 14, 467-537.

[4] Muller, G. (1995), Intermodal Freight Transportation, IANAIntermodal Association of North America e Eno Transportation Foundation. Inc., Virginia, USA.

[5] Barnhart, C., \& Ratliff, H.D.(1993), Modelling intermodal routing, Journal of Business Logistics 14, 205.

[6] B. S. Boardman, E. M. Malstrom, D. P. Butler, M. H. Cole (1997), Computer assisted routing of intermodal shipments, Computers and Industrial Engineering 33, 311-314.

[7] Bookbinder, J.H., \& Fox, N.S. (1998), Intermodal routing of Canada-Mexico shipments under NAFTA, Transportation Research Part E: Logistics and Transportation Review 34, 289303.

[8] Southworth, F.,\& Peterson B.E. (2000), Intermodal and international freight network modelling, Transportation Research Part C: Emerging Technologies 8, 147-166. 
[9] Chang, T.S. (2008), Best routes selection in international intermodal networks, Computers \& operations research 35, 2877. 2891.

[10] Cho, J.H., Kim, H.S., \& Choi, H.R. (2012), An intermodal transport network planning algorithm using dynamic programming - a case study: from Busan to Rotterdam in intermodal freight routing, Applied Intelligence 36, 529-541.

[11] Hu, Z.H. (2011), A container multimodal transportation scheduling approach based on immune affinity model for emergency relief, Expert Systems with Applications 38, 2632-2639.

[12] Kai, K., Haijiao, N., Yuejie, Z., \& Weicun, Z. (2010), Research on improved integrated optimization model for mode and Route in multimodal transportation basing on the PSO-ACO, IEEE Logistics Systems and Intelligent Management 3, 14451449.

[13] Yang, X., Low, J.M., \& Tang, L.C. (2011), Analysis of intermodal freight from China to Indian Ocean: a goal programming approach, Journal of Transport Geography 19, 515-527.

[14] Boile, M.P. (2000), Intermodal transportation network analysisA GIS application, IEEE Electro technical Conference, Vol. 2, pp. 660-663.

[15] Standifer, G.C., \& Walton, C.M. (2000), Development of a GIS model for intermodal freight.

[16] Winebrake, J.J., Corbett, J.J., Falzarano, A., Hawker, J.S., Korfmacher, K., Ketha, S., \& Zilora, S. (2008), Assessing energy, environmental, and economic tradeoffs in intermodal freight transportation, Journal of the Air \& Waste Management Association 58, 1004-1013.

[17] Comer, B., Corbett, J.J., Hawker, J.S., Korfmacher, K., Lee, E.E., Prokop, C., \& Winebrake J.J. (2010), Marine vessels as substitutes for heavy-duty trucks in Great Lakes freight transportation, Journal of the Air \& Waste Management Association 60 884-890.

[18] Rodrigue, J.P., Comtois, C., \& Slack, B., The geography of transport systems, Routledge, (2009). 